\title{
Eficiência de Trichoderma harzianum e Gliocladium viride na redução da incidência de Botrytis cinerea em tomateiro cultivado sob ambiente protegido
}

\author{
Efficiency of Trichoderma harzianum and Gliocladium viride in decreasing the incidence of Botrytis \\ cinerea in tomato cultivated in protected environment
}

\author{
Bruno Brito Lisboa ${ }^{\mathrm{I}}$ Carla Centeno Bochese ${ }^{\mathrm{II}}$ Luciano Kayser Vargas ${ }^{\mathrm{I}}$ \\ José Ricardo Pfeifer SilveiraI Bernadete Radin \\ Andréia Mara Rota de Oliveira ${ }^{I I}$
}

\section{RESUMO}

\begin{abstract}
A produção de tomates no Estado do RS ocupa um importante papel sócio-econômico, que pode ser constatado pelo crescimento do cultivo dessa hortaliça em ambiente protegido. Essa técnica permite a produção de tomates em período de entressafra; no entanto, ocorrem também condições favoráveis para o desenvolvimento de doenças fúngicas como o mofo cinzento provocado por Botrytis cinerea. O surgimento de raças de patógenos resistentes a fungicidas químicos vem fazendo com que o controle biológico torne-se uma alternativa necessária. Neste trabalho foi realizada seleção in vitro de 24 isolados do fungo Trichoderma harzianum e 12 de Gliocladium viride que inibiram o desenvolvimento do patógeno B. cinerea. Foram selecionados dois isolados (TRIC30 e GLIO-10) para serem testados em experimentos em condições de campo com tomates cultivados sob ambiente protegido, nos quais a pulverização foliar semanal com uma suspensão com $2 \times 107$ conídios $\mathrm{mL}^{-1}$ reduziu significativamente a incidência do mofo cinzento, enquanto a aplicação dos antagonistas nas sementes, no substrato e na cova, no momento do plantio, não reduziu a incidência do patógeno.
\end{abstract}

Palavras-chaves: Lycopersicum esculentum, controle biológico, mofo cinzento, estufa, seleção in vitro.

\section{ABSTRACT}

The production of tomato in the State of Rio Grande do Sul performs an important economical and social role that can be evidenced by the increase in cultivation of this vegetable in protected environment. This practice allows the production of tomato during the off-season periods. However, it can also promote favorable conditions to the development of gray mold caused by Botrytis cinerea, and the arising of pathogen races resistant to fungicides is turning biological control into a necessary alternative. In the present work, an in vitro selection among 24 isolates of the fungus Trichoderma harzianum and 12 of Gliocladium viride that inhibited the development of the pathogen B. cinerea was carried out. Two isolates (TRIC-30 e GLIO-10) were selected to be tested in an experiment in field conditions with tomatoes cultivated under protected environment. In this experiment, the weekly foliar pulverization of a suspension with $2 \times 107$ conidia $\mathrm{mL}^{-1}$ significantly decreased the incidence of gray mold, while the application of the antagonists on the seeds, substrate and seed hole during seeding did not reduced the incidence of the pathogen.

Key words: Lycopersicum esculentum, biological control, gray mold, greenhouse, in vitro selection.

\section{INTRODUÇÃO}

A cadeia de produção envolvendo a cultura do tomateiro, Lycopersicum esculentum Mill, representa para o Estado do Rio Grande do Sul um setor de grande interesse sócio-econômico. Resultados de 2004 mostravam que o RS produziu 97 mil toneladas, numa área de 2.572 hectares (IBGE, 2004), empregando grande parte da mão de obra das regiões produtoras.

A produção vegetal, em ambiente protegido, é considerada mundialmente como um sistema de produção que possibilita o controle parcial dos efeitos negativos do clima, através da acentuada modificação do ambiente onde determinada espécie é cultivada, o que torna possível a produção vegetal fora da época normal, com aumento no período de colheita e maior produção (BRANDÃO FILHO \& CALLEGARI, 1999).

IFEPAGRO - Fundação Estadual de Pesquisa Agropecuária, Rua Gonçalves Dias 570, 90130-060, Porto Alegre, RS, Brasil. E-mail: bruno@fepagro.rs.gov.br. Autor para correspondência.

IIUniversidade Estadual do Rio Grande do Sul (UERGS), Novo Hamburgo, RS, Brasil. 
Os estudos sobre rendimento de tomate em estufa, no Brasil, indicam elevadas produtividades, com rendimentos entre 150 e 160 t ha $^{-1}$ (CALVETE et al., 1992; STRECK et al., 1992). Cabe destacar que o rendimento médio da cultura do tomateiro no Brasil, segundo o IBGE (2004), está ao redor de $58 \mathrm{t} \mathrm{ha}^{-1}$.

Avaliando a ocorrência de moléstias em tomateiro cultivado sob ambiente protegido, em experimento realizado em quatro municípios da região central do RS, BLUME \& JARA (2004) identificaram o mofo cinzento, causado por Botrytis cinerea, como uma das principais doenças que atacam a cultura, sendo que a umidade relativa do ar foi o fator determinante no desenvolvimento do patógeno.

O mofo cinzento pode causar danos em todas as partes da planta. A infecção pode iniciar nas pétalas das flores e progredir para folíolos e, posteriormente, para ramos e frutos. Para ocorrer a infecção, o patógeno, necessita de temperatura entre 18 e $23^{\circ} \mathrm{C}$, sendo que temperaturas acima de $24^{\circ} \mathrm{C}$ inibem a germinação dos conídios (VALE et al., 2004).

A importância das doenças causadas por

B. cinerea fez com que o emprego de fungicidas químicos se tornasse a principal forma de controle desse patógeno, o que acabou gerando o surgimento de resistência do fungo a esses agrotóxicos. ELAD et al. (1995) constataram, em experimentos realizados em Israel e no norte da Itália, utilizando fungicidas dos grupos dos benzimidazóis e das carboximidas em cultivo de tomate em estufas, que a erradicação completa do mofo cinzento dificilmente é alcançada.

Atualmente, a prevenção à resistência está sendo buscada por meio do manejo integrado dessa moléstia fúngica. Nesse contexto, são preconizadas medidas como uso de variedades resistentes, rotação de culturas, métodos culturais, físicos e métodos biológicos de controle (SOUZA \& DUTRA, 2003).

$\mathrm{O}$ controle biológico já há muitos anos tornou-se um frutífero campo de pesquisas; porém, esse esforço resultou em um reduzido número de produtos comerciais de organismos biocontroladores de doenças vegetais. Por outro lado, dentre esses poucos insumos, existem aqueles que produzem excelentes resultados, como formulados à base de Trichoderma harzianum (HARMAN, 2000).

A utilização de testes in vitro para a seleção de organismos biocontroladores é uma importante ferramenta para a avaliação de um grande número de isolados. Por outro lado, a execução de experimentos em condições de campo é fundamental para validar os trabalhos realizados em laboratório $(\mathrm{LYNCH}, 1987$; LINHARES et al., 1995).

O objetivo do presente trabalho foi obter isolados de Trichoderma sp. e Gliocladium sp. capazes de controlar B. cinerea in vitro e em tomateiro cultivado sob ambiente protegido.

\section{MATERIAL E MÉTODOS}

Para o isolamento dos fungos biocontroladores Trichoderma e Gliocladium, foi realizada a coleta de amostras do filoplano, rizoplano e solo, em lavouras de produção comercial de tomate nos municípios de Porto Alegre, Viamão e Caxias do Sul.

Em condições de assepsia, foram pesadas, separadamente, $10 \mathrm{~g}$ de amostra de folhas, raízes e solo, e adicionadas a $90 \mathrm{~mL}$ de solução salina $(0,85 \% \mathrm{NaCl})$ estéril, com agitação por $20 \mathrm{~min}$. A solução foi diluída até a concentração de $10^{-2}$. Alíquotas de $100 \mu 1$ foram pipetadas em placas de Petri com meio Batata-DextroseAgar (BDA) e espalhadas com alça de Drigalsky. As placas foram incubadas em câmara de crescimento com temperatura de $23^{\circ} \mathrm{C}$ sem o uso de iluminação. As colônias com as características morfológicas de Trichoderma sp. e Gliocladium sp. foram repicadas isoladamente e incubadas novamente. Os antagonistas foram identificados em termos de espécie de acordo com a chave de identificação de DOMSCH et al. (1980).

$\mathrm{O}$ isolado de $\boldsymbol{B}$. cinerea utilizado neste trabalho foi obtido de uma planta de tomateiro apresentando sintomas de mofo cinzento, em lavoura de produção comercial, através da realização de câmara úmida a $23^{\circ} \mathrm{C}$, e com o posterior isolamento monospórico em meio BDA. Todos os isolados foram preservados em tubos de ensaio contendo BDA e em papel filtro embebido com solução de esporos, mantidos à temperatura de $4^{\circ} \mathrm{C}$.

A avaliação do potencial de controle in vitro dos antagonistas foi realizada através do método de culturas pareadas (MARIANO, 1993). A aplicação desse método consistiu na produção de culturas puras dos antagonistas (quatro dias de incubação a $23^{\circ} \mathrm{C}$ ) e do fitopatógeno (sete dias de incubação a $23^{\circ} \mathrm{C}$ ) em BDA, de onde se retiraram discos de $5 \mathrm{~mm}$ de diâmetro. Dois discos, um contendo estruturas do antagonista e outro do fitopatógeno, foram depositados, diametralmente opostos, em placas com BDA para a avaliação de inibição. Placas com BDA contendo apenas o patógeno foram utilizadas como controle. As culturas foram incubadas por sete dias na temperatura 
de $23^{\circ} \mathrm{C}$, quando foram medidos os diâmetros das colônias do fitopatógeno e, após, comparados com o crescimento do controle e determinada a porcentagem relativa de inibição.

Os isolados também foram avaliados quanto à produção de conídios e ao crescimento micelial em meio de cultura BDA, no período de $48 \mathrm{~h}$ em temperatura de $23^{\circ} \mathrm{C}$. Esse ensaio foi realizado separadamente ao anterior, sendo que, para tal, discos de $5 \mathrm{~mm}$ de culturas puras dos antagonistas foram colocados no centro de placas de petri com BDA. O crescimento foi mensurado pela medida do diâmetro das colônias. A determinação da concentração de esporos foi realizada com o emprego de câmara de Neubauer, segundo GUIMARÃES et al. (2004).

Conforme os resultados das avaliações in vitro, relacionados com o controle de $\boldsymbol{B}$. cinerea, foram escolhidos dois isolados, sendo um de Trichoderma harzianum e outro de Gliocladium viride, para a realização dos testes em condições de ambiente protegido, no Centro de Pesquisa de Saúde Animal da FEPAGRO, no município de Eldorado do Sul.

Para a instalação do experimento, foram produzidas mudas de tomate da cultivar Santa Clara através de semeadura em bandeja de poliestireno, utilizando-se substrato comercial. A estufa utilizada foi um túnel alto nas dimensões de 5,0 x 28 × 2,5m, contando com quatro fileiras de plantio, com 144 plantas por ensaio. O túnel foi dividido ao meio por uma saia plástica, sendo cada metade destinada para a avaliação de um antagonista. As mudas foram plantadas no espaçamento de $0,30 \mathrm{~m} \times 1 \mathrm{~m}$, perfazendo uma total de 288 plantas no total da estufa.

A infecção do patógeno ocorreu naturalmente, principalmente pelo fato de que o cultivo do tomateiro foi realizado em período de outono/ inverno, caracterizado por alta umidade relativa do ar e baixas temperaturas, condições favoráveis para o desenvolvimento de $\boldsymbol{B}$. cinerea.

$\mathrm{O}$ experimento contava com os seguintes tratamentos para cada biocontrolador: $\mathrm{T} 0=$ Testemunha (pulverização de água destilada); T1 = Aplicação do biocontrolador na semente, substrato e na cova; T2 = Aplicação foliar semanal a partir da $1^{\circ}$ floração e T3 = $\mathrm{T} 1+\mathrm{T} 2$.

Para a inoculação das sementes (T1 e T3), estas foram imersas em uma suspensão de $4 \times 107$ conídios $\mathrm{mL}^{-1}$ dos antagonistas crescidos em grãos de sorgo por cinco minutos. Foi utilizado o mesmo inóculo para aplicações no substrato de semeadura $\left(5 \mathrm{~mL} \mathrm{~kg}^{-1}\right)$ e nas covas $\left(5 \mathrm{~mL} \mathrm{cova}^{-1}\right)$, no momento do transplante das mudas. As pulverizações aéreas foram efetuadas semanalmente a partir da primeira floração através de suspensões com concentrações de 2 x 107 conídios $\mathrm{mL}^{-1}$ de cada antagonista multiplicados em grãos de sorgo. As aplicações foram realizadas através de um pulverizador costal, e o volume aplicado variou de acordo com o desenvolvimento da cultura, sendo o suficiente para promover a cobertura integral da parte aérea.

As mudas receberam adubação na base com formulação de adubo químico, de acordo com o resultado da análise do solo da estufa, sendo que o $\mathrm{P}$ e o K foram aplicados no sulco oito dias antes do transplante, bem como $4 \mathrm{~g}$ de uréia por planta. Também foi realizada adubação de cobertura com nitrogênio na forma de uréia parcelada em duas vezes: $8 \mathrm{~g}$ de uréia planta $^{-1}$ aos 15 e 30 dias após o plantio. As plantas foram tutoradas com fio de ráfia e a desbrota foi realizada de maneira a deixar duas hastes em cada planta. A temperatura e a umidade relativa do ar foram monitoradas através de um termoigrógrafo.

A avaliação da doença foi realizada através da contagem de folhas por planta que apresentavam sintomas do mofo cinzento, para assim determinar a incidência da moléstia expressa em porcentagem. As avaliações iniciaram a partir dos primeiros sintomas do mofo cinzento nas folhas, os quais ocorreram simultaneamente em todos os tratamentos, sendo que as coletas de dados foram realizadas a cada sete dias.

As informações obtidas foram integradas em curvas de progresso da doença e em áreas abaixo da curva de progresso da doença (AACPD) em cada tratamento (MORAES et al., 2006).

Os dados das avaliações in vitro foram analisados segundo um delineamento totalmente casualizado, com quatro repetições cada. $\mathrm{O}$ grau de associação entre as variáveis foi analisado por meio de análises de correlação.

O experimento realizado em condições de cultivo sob ambiente protegido foram conduzidos em delineamento em blocos casualizados com três repetições, com 12 plantas por parcela.

Os dados foram submetidos à análise de variância e as médias comparadas pelos testes de Schott \& Knott e Tukey, utilizando-se o programa computacional Sisvar para Windows versão 4.0. (FERREIRA, 2000), com nível de erro de 5\%.

\section{RESULTADOS E DISCUSSÃO}

Isolamento e seleção in vitro de antagonistas

Durante a fase de seleção de isolados dos antagonistas, foram obtidos 36 isolados. Desses, 24 
foram classificados como Trichoderma harzianum e 12 como Gliocladium viride. Os dados demonstram que todos os isolados de Trichoderma e Gliocladium tiveram alguma ação inibitória in vitro sobre o isolado de B. cinerea (tabela 1), sendo que para este parâmetro encontrou-se correlação positiva $(\mathrm{r}=0,461$ e $\mathrm{P}=0,0463)$ com a taxa de crescimento micelial, embora com baixa associação entre as duas variáveis. Já a produção de conídios, apesar de estar relacionada com a taxa de crescimento $(\mathrm{r}=0,659$ e $\mathrm{P}=0,0000124)$, não apresentou correlação com a inibição $(\mathrm{r}=0,278$ e $\mathrm{P}=0,101)$. Mesmo não havendo uma elevada correlação entre inibição in vitro com os outros dois parâmetros, a produção de conídios e a taxa de crescimento micelial podem potencialmente se constituir em importantes características, no que se refere ao desempenho dos antagonistas em condições in vivo, tendo em vista que o sucesso de um agente de controle biológico em condições de campo também depende de sua capacidade de colonizar a cultura a ser protegida (PARKE, 1991).

Para a realização do experimento a campo, foram selecionados os isolados TRIC-30 (T. harzianum) e GLIO-10 (G viride), em função do desempenho destes nas avaliações in vitro e também por ter-se optado em utilizar organismos dos dois gêneros no trabalho em condições de estufa. O critério para a seleção de TRIC30, para utilizá-lo no experimento a campo, foi o seu desempenho superior no teste de pareamento competitivo, de acordo com a tabela 1 . Em relação à escolha do isolado GLIO-10, foram preponderantes a taxa de crescimento micelial e a produção de conídios, características que o diferenciaram dos outros isolados de G. viride.

Os primeiros sintomas surgiram depois de 64 dias após o transplante, porém foi constatada a necrose de flores causada por B. cinerea cerca de um mês antes do surgimento dos sintomas foliares, o que provavelmente constituiu a infecção primária dentro do experimento. Os períodos em que foram constatados os sintomas nas flores e depois nas folhas coincidiram com temperaturas médias diárias abaixo de $20^{\circ} \mathrm{C}$ e umidade relativa do ar acima de 94\%, condições que, segundo HAUSBECK (1996) e ELAD et al. (1996), são favoráveis para o desenvolvimento de doenças causadas por $\boldsymbol{B}$. cinerea.

O mofo cinzento trata-se de uma moléstia policíclica, na qual o potencial de inóculo do patógeno durante o ciclo da cultura é um dos principais fatores que determinam o grau de incidência e severidade da doença, sendo ainda mais importante no início do desenvolvimento das plantas (BERGAMIM FILHO, 1995). Tanto o isolado TRIC-30 quanto o GLIO-10, em aplicação foliar do inóculo dos agentes biocontroladores semanalmente, induziram o retardo no desenvolvimento da doença. A figura 1 mostra a

Tabela 1 - Ação inibitória para Botrytis cinerea, crescimento micelial e produção de conídios em meio de cultura BDA, de Trichoderma harzianum e Gliocladium viride

\begin{tabular}{|c|c|c|c|}
\hline Isolados & $\begin{array}{l}\text { \% Inibição } \\
\text { Botrytis } \\
\text { cinerea }\end{array}$ & $\begin{array}{l}\text { Crescimento } \\
\text { micelial }\end{array}$ & $\begin{array}{c}\text { Produção de } \\
\text { conídios X } \\
50.000\end{array}$ \\
\hline \multicolumn{4}{|c|}{ Trichoderma harzianum } \\
\hline TRIC-30 & $74,41 \mathrm{a}$ & $6,96 \mathrm{~b}$ & $21,66 \mathrm{~b}$ \\
\hline TRIC-36 & $72,49 \mathrm{a}$ & $6,70 \mathrm{~b}$ & $15,0 \mathrm{c}$ \\
\hline TRIC-35 & $70,42 \mathrm{a}$ & $7,23 \mathrm{a}$ & $47,33 \mathrm{~b}$ \\
\hline TRIC-17 & $70,42 \mathrm{~b}$ & $4,13 \mathrm{~d}$ & $1,33 \mathrm{~d}$ \\
\hline TRIC-33 & $70,42 \mathrm{~b}$ & $7,5 \mathrm{a}$ & $48,0 \mathrm{~b}$ \\
\hline TRIC-37 & $62,58 \mathrm{~b}$ & $5,93 \mathrm{c}$ & $55,66 \mathrm{~b}$ \\
\hline TRIC-11 & $59,62 \mathrm{c}$ & $4,83 \mathrm{c}$ & $26,66 \mathrm{~b}$ \\
\hline TRIC-29 & $58,14 \mathrm{~d}$ & $7,23 \mathrm{a}$ & $33,0 \mathrm{~b}$ \\
\hline TRIC-15 & $58,14 \mathrm{~d}$ & $4,43 \mathrm{c}$ & $4,0 \quad \mathrm{~d}$ \\
\hline TRIC-31 & $57,59 \mathrm{~d}$ & $6,60 \mathrm{~b}$ & $5,33 \quad \mathrm{~d}$ \\
\hline TRIC-21 & $57,70 \mathrm{~d}$ & $4,86 \mathrm{c}$ & $17,66 \mathrm{c}$ \\
\hline TRIC-32 & $57,11 \mathrm{~d}$ & $7,46 a$ & $28,0 \mathrm{~b}$ \\
\hline TRIC-19 & $57,11 \mathrm{~d}$ & $4,6 \mathrm{c}$ & $1,67 \quad \mathrm{~d}$ \\
\hline TRIC-03 & $57,11 \mathrm{~d}$ & $3,83 \mathrm{~d}$ & $3,33 \quad \mathrm{~d}$ \\
\hline TRIC-34 & $56,66 \mathrm{~d}$ & $7,63 \mathrm{a}$ & $27,33 \mathrm{~b}$ \\
\hline TRIC-18 & $56,22 \mathrm{~d}$ & $4,90 \mathrm{c}$ & $9,0 \quad \mathrm{~d}$ \\
\hline TRIC-08 & $56,22 \mathrm{~d}$ & $7,83 \mathrm{a}$ & $120,0 \mathrm{a}$ \\
\hline TRIC-14 & $54,64 \mathrm{e}$ & $3,76 \quad d$ & $2,33 \quad \mathrm{~d}$ \\
\hline TRIC-24 & 53,70 e & $4,86 \mathrm{c}$ & $9,0 \quad \mathrm{~d}$ \\
\hline TRIC-16 & 51,19 e & $5,33 \mathrm{c}$ & $6,33 \mathrm{~d}$ \\
\hline TRIC-23 & 50,30 e & $4,76 \mathrm{c}$ & $15,66 \mathrm{c}$ \\
\hline TRIC-22 & $46,26 \mathrm{f}$ & $4,23 \mathrm{c}$ & $3,33 \quad \mathrm{~d}$ \\
\hline TRIC-26 & $43,35 \mathrm{f}$ & $4,6 \mathrm{c}$ & $2,33 \quad \mathrm{~d}$ \\
\hline TRIC-20 & $42,31 \quad \mathrm{f}$ & $4,16 \mathrm{c}$ & $6,0 \quad \mathrm{~d}$ \\
\hline $\mathrm{CV} \%$ & 18,21 & 19,23 & 22,15 \\
\hline Média geral & 58,87 & 5,59 & 21,24 \\
\hline \multicolumn{4}{|c|}{ Gliocladium viride } \\
\hline GLIO-12 & $60,06 a$ & $3,66 \mathrm{~b}$ & $9,66 \mathrm{~b}$ \\
\hline GLIO-07 & $60,06 a$ & $4,43 a$ & $5,66 \mathrm{c}$ \\
\hline GLIO-10 & $58,14 \mathrm{a}$ & $5,96 a$ & $18,33 \mathrm{a}$ \\
\hline GLIO-06 & $57,70 \mathrm{a}$ & $5,96 \mathrm{a}$ & $13,0 \mathrm{~b}$ \\
\hline GLIO-13 & $56,66 \mathrm{~b}$ & $2,93 \mathrm{c}$ & $8,66 \mathrm{~b}$ \\
\hline GLIO-14 & $56,66 \mathrm{~b}$ & $4,16 \mathrm{~b}$ & $7,66 \mathrm{~b}$ \\
\hline GLIO-04 & $56,22 \mathrm{~b}$ & $5,33 \mathrm{a}$ & $6,66 \mathrm{~b}$ \\
\hline GLIO-05 & $56,22 \mathrm{~b}$ & $4,13 \mathrm{~b}$ & $4,0 \mathrm{c}$ \\
\hline GLIO-01 & $55,14 \mathrm{~b}$ & $4,46 \mathrm{~b}$ & $23,0 \mathrm{a}$ \\
\hline GLIO-02 & $53,66 \mathrm{~b}$ & $4,3 \mathrm{~b}$ & $10,0 \mathrm{~b}$ \\
\hline GLIO-09 & $51,19 \mathrm{c}$ & $3,46 \mathrm{c}$ & $7,0 \mathrm{~b}$ \\
\hline GLIO-11 & $50,74 \mathrm{c}$ & $3,5 \mathrm{c}$ & $3,0 \mathrm{c}$ \\
\hline $\mathrm{CV} \%$ & 15,35 & 21,25 & 19,45 \\
\hline Média geral & 56,03 & 4,35 & 9,72 \\
\hline
\end{tabular}

Médias não seguidas de mesma letra diferem pelo teste de Schott $\&$ Knott a 5\% de probabilidade de erro.

Ciência Rural, v.37, n.5, set-out, 2007. 
redução inicial da infecção em relação aos tratamentos sem pulverização de antagonistas.

Como as avaliações dos dois antagonistas foram realizadas em uma única estufa plástica, a influência da testemunha (T0) e dos tratamentos com inóculo na semente, substrato e cova (T1), isto é, aqueles que apresentaram o mais rápido crescimento da doença, aumentaram a pressão de inóculo do patógeno nos demais tratamentos, fazendo com que já na quarta avaliação, 21 dias após a primeira avaliação, a porcentagem de folhas com sintomas de mofo cinzento entre os tratamentos fosse semelhante.

Observando-se a tabela 2, que demonstra o resultados das AACPD para cada tratamento, pode-se notar que estes distinguiram-se em dois grupos. $\mathrm{O}$ grupo T2 e T3 (com aplicação foliar) diferiu significativamente do grupo T0 e T1 (sem aplicação foliar), para os dois agentes de controle biológico. Nas condições em que foi realizado o experimento, o fato de se inocular as sementes, o substrato e a cova de plantio com os bioantagonistas (T1) não gerou diferenças significantes em relação à testemunha (T0). Além disso, este tratamento, quando somado à aplicação foliar semanal do antagonista (T3), não aumentou o controle do mofo cinzento se comparado apenas com a aplicação foliar isolada (T2). O fato de a inoculação dos antagonistas em sítios separados (semente, substrato e cova) da parte aérea das plantas, na qual ocorre o mofo cinzento, não ter gerado resposta positiva quanto ao controle da doença indica a não-ocorrência de um possível processo de indução de resistência, diferentemente dos resultados de MEYER et al. (1998), que obtiveram controle entre 25 a $100 \%$ do mofo cinzento em tomateiro, através deste mecanismo, promovido pela inoculação de Trichoderma harzianum. Por outro lado, a pulverização semanal demonstrou-se eficiente como ferramenta no manejo de controle de B. cinerea, principalmente devido à constante renovação de uma alta concentração de inóculo dos antagonistas.

\section{CONCLUSÕES}

A utilização de Trichoderma harzianum e Gliocladium viride nas sementes, no substrato de semeadura e na cova não aumenta o controle do mofo cinzento em tomateiro.

a)

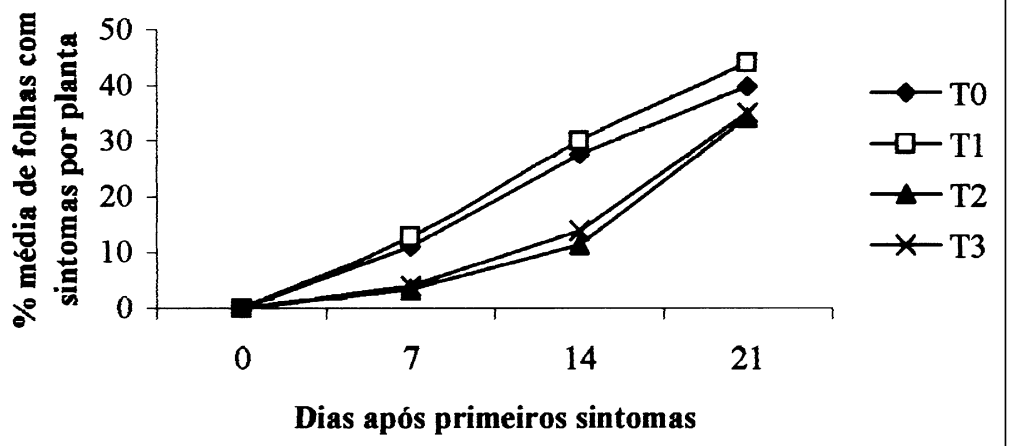

b)

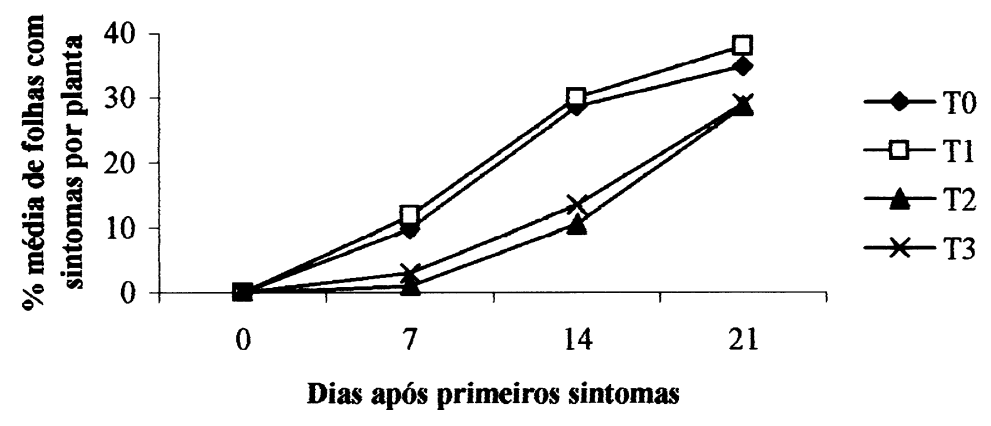

Figura 1 - Evolução da incidência do mofo cinzento causado por $\boldsymbol{B}$. cinerea em porcentagem de folhas por planta com sintomas em quatro avaliações. T0 = testemunha (pulverização de água destilada), T1 = aplicação do biocontrolador na semente, no substrato e na cova; T2 = aplicação foliar semanal a partir da $1^{\text {a }}$ floração; T3 = T1+T2 em experimentos com a) Trichoderma harzianum e b) Gliocladium viride. 
Tabela 2 - Área abaixo da curva de progresso da doença (AACPD) provocada por B. cinerea em tomateiro cultivar "Santa Clara", em experimento em estufa comercial, avaliando os isolados TRIC-30 (Trichoderma harzianum) e GLIO-10 (Gliocladium viride). T0 = Testemunha (pulverização de água destilada); $\mathrm{T} 1$ = Aplicação do biocontrolador na semente, no substrato e na cova; T2 = Aplicação foliar semanal a partir da $1^{\circ}$ floração; $\mathrm{T} 3=\mathrm{T} 1+\mathrm{T} 2$.

\begin{tabular}{|c|c|c|}
\hline Tratamentos & \multicolumn{2}{|c|}{ AACPD } \\
\hline \multicolumn{3}{|c|}{ Trichoderma harzianum } \\
\hline $\mathrm{T} 2$ & $182.0 \mathrm{a}$ & \\
\hline $\mathrm{T} 3$ & $217.6 \mathrm{a}$ & \\
\hline T0 & $392.6 \mathrm{~b}$ & $\mathrm{~b}$ \\
\hline $\mathrm{T} 1$ & $435.3 \mathrm{~b}$ & $\mathrm{~b}$ \\
\hline $\mathrm{CV} \%$ & 11,71 & \\
\hline Média Geral: & 306,92 & \\
\hline \multicolumn{3}{|c|}{ Gliocladium viride } \\
\hline $\mathrm{T} 2$ & $222.9 \mathrm{a}$ & \\
\hline $\mathrm{T} 3$ & $247.2 \mathrm{a}$ & \\
\hline T0 & 409.5 & $\mathrm{~b}$ \\
\hline $\mathrm{T} 1$ & 454.2 & $\mathrm{~b}$ \\
\hline $\mathrm{CV} \%$ & 13,22 & \\
\hline Média Geral & 333,48 & \\
\hline
\end{tabular}

"Médias não seguidas de mesma letra diferem pelo teste de Tukey a $5 \%$ de probabilidade de erro.

Os isolados TRIC-30 e GLIO-10 foram eficazes em cultivo protegido, quando utilizada a aplicação foliar semanal, demonstrando que esses antagonistas possuem potencial para tornarem-se ferramentas para o manejo de $\boldsymbol{B}$. cinerea em cultivo do tomateiro em ambiente protegido.

\section{REFERÊNCIAS}

BERGAMIN FILHO, A.A Epidemia como um sistema. In: BERGAMIN FILHO, A. et al. Manual de fitopatologia. 3.ed. São Paulo: Ceres, 1995. v.1. cap. 29, p.574-602.

BLUME, E.; JARA, A. Moléstias em tomateiro cultivado em estufas plásticas em quatro municípios da região central do Rio Grande do Sul, Brasil. Ciência Rural, v.34, n.3, p.661-666, 2004.

BRANDÃO FILHO, J.U.T.; CALLEGARI, O. Cultivo de hortaliças em solo em ambiente protegido. Informe Agropecuário. v.20, p.64-68, 1999.

CALVETE, E.O. et al. Avaliação de linhagens e cultivares de tomate (Lycopersicon esculentum Mill.) em estufa plástica na região de Passo Fundo- RS. In: ENCONTRO DE HORTALIÇAS DA REGIÃO SUL, 8.; ENCONTRO DE PLASTICULTURA DA REGIÃO SUL, 5., 1992, Porto Alegre. Resumos... Porto Alegre: SOB/UFRGS, 1992. p.49.

DOMSCH, K.H. et al. Compendium of soil fungi. London: Academic, 1980. 630p.
ELAD, Y. et al. Managing Botrytis cinerea on tomatoes in greenhouses in the Mediterranean. Crop Protection, v.14, n.2, p.105-109, 1995.

ELAD, Y. et al. Biological control of Botrytis-incited diseases and powdery mildews in greenhouses crops. Crop Protection, v.15, n.3, p.229-240, 1996.

FERREIRA, D.F. Análises estatísticas por meio do Sisvar para Windows versão 4.0. In: REUNIÃO ANUAL DA REGIÃO BRASILEIRA DA SOCIEDADE INTERNACIONAL DE BIOMETRIA, 45., 2000, São Carlos. Resumos... São Carlos: UFSCAR, 2000. p.255-258.

GUIMARÃES C.O. et al. Pressão de aplicação com pulverizador de barra e eficiência de bioinseticidas fúngicos comerciais. Pesquisa Agropecuária Brasileira, v.39, n.12, p.1177-1182, 2004.

HARMAN, G. Myths and dogmas of biocontrol. Plant Disease, v.84 n.4, p.377-393, 2000.

HAUSBECK, K. Mananging Botrytis cinerea in greenhousegrow flowers crops. Plant Disease, v.80, n.11, p.1212-1219, 1996.

IBGE. Produção agrícola municipal. Rio de Janeiro: (Instituto Brasileiro de Geografia e estatística), 2004. v.31.

LINHARES, A.I. et al. Avaliação da amplitude de ação antagonística de microrganismos epífitas do trigo sobre o crescimento radial de Drechslera tritici-repentis. Revista Brasileira de Agrociência, v.1, n.3, p.119-126, 1995.

LYNCH, J.M. In vitro identification of Trichoderma harzianum as a potential antagonist of plant pathogens. Current Microbiology, v.16, p.49-53, 1987.

MARIANO, R.L.R. Métodos de seleção in vitro para o controle microbiológico de patógenos de plantas. Revisão Anual de Patologia de Plantas, v.1, p.369-409, 1993.

MEYER, $\mathrm{G}$ et al. Induced systemic resistance in Trichoderma harzianum T39 biocontrol of Botrytis cinerea. European Journal of Plant Pathology, v.104, p.279-286, 1998.

MORAES, S.R.G. et al. Efeito de fontes de silício na incidência e na severidade da antracnose do feijoeiro. Fitopatologia Brasileira, v.31, n.1, p.69-75, 2006.

PARKE, J.L. Root colonization by indigenous and introduced microorganisms. In: KEISTER, D.L.; GREGAN, P.B. The rhizosphere and plant growth. Boston: Kluwer Academic, 1991. p.33-42.

SOUZA, P.; DUTRA, M. Fungicidas no controle e manejo de doenças de plantas. Lavras: UFLA, 2003. 174p.

STRECK, N.A. et al. Influência da população de plantas sobre o rendimento e qualidade dos frutos de tomateiro cultivado em estufa plástica. In: ENCONTRO DE HORTALIÇAS DA REGIÃO SUL, 8.; ENCONTRO DE PLASTICULTURA DA REGIÃo SUL, 5., 1992, Porto Alegre. Resumos... Porto Alegre: SOB/UFRGS, 1992. p.47.

VALE, F.X.R. et al. Manejo integrado das doenças do tomateiro: epidemiologia e controle. In: ALVARENGA, M.A.R. Tomate: produção em campo, em casa-de-vegetação e em hidroponia. Lavras: UFLA, 2004. Cap.9, p.213-308. 